\title{
RAISING VALUE AND SUSTAINABILITY AWARENESS FOR CRITICAL MATERIALS: A SERIOUS GAME FOR THE AEROSPACE SECTOR
}

\author{
G. W. Scurati ${ }^{1, \otimes}$, J. W. Nylander ${ }^{2}$, S. I. Hallstedt ${ }^{3}$, F. Ferrise ${ }^{1}$ and M. Bertoni ${ }^{3}$ \\ ${ }^{1}$ Politecnico di Milano, Italy, ${ }^{2}$ GKN Aerospace, Sweden, ${ }^{3}$ Blekinge Institute of Technology, Sweden \\ $\triangle$ giuliawally.scurati@polimi.it
}

\begin{abstract}
Aviation strives today to include environmental and social considerations as drivers for decision making in design. This paper proposes a serious game to raise awareness of the value and cost implications of being 'sustainability compliant' when developing aerospace sub-systems and components. After describing the development of the game, from needfinding to prototyping and testing, the paper discusses the results from verification activities with practitioners, revealing the ability of the game to raise sustainability awareness and support negotiation across disciplinary boundaries in design.
\end{abstract}

Keywords: serious game, sustainability, decision making, risk management, critical materials

\section{Introduction}

Public attention on environmental and social sustainability is higher than ever, leading governments and institutions to adopt a series of measures, regulations and even bans to cope with this emerging challenge. At the same time, sustainability is increasingly recognized as a key innovation capability for manufacturers (Lubin and Esty 2010), fuelling the development of innovative technical solutions and business ideas (Willard 2012). In recent years, this has triggered the rapid evolution of the sustainable product development discipline. Due to its broader system perspective, the latter challenges existing methods and tools for design and development, forcing the engineering team to move from product thinking to system thinking. This emphasizes the need for leveraging collaboration and communication among experts from several disciplines, who must be involved since an early design stage to identify optimal solutions both from a functional and sustainability perspective. Processes and tools for sustainable product development shall then be conceived to facilitate participation in the definition of the evaluation criteria for products, mixing value- and sustainability-related considerations (Watz and Hallstedt, 2019). Also, the information carried by disciplinary experts needs to be modelled and displayed during the evaluation of product concepts, so to identify optimal solutions from the perspectives of technological feasibility, user-acceptability, and sustainability (Bertoni et al., 2015).

Nowadays, the aviation industry is at the forefront of the quest for reducing (and reversing) environmental impact, while still answering the increasing demand for mobility required by our economy (Kousoulidou and Lonza, 2016). Air transport has shown a steady increased in CO2 emissions in the last decades, going from 88 to 171 million tonnes between 1990 and 2016 for all flights departing from EU28 and EFTA (EASA, 2019). The Strategic Research Agenda, published by the Advisory Council for Aeronautics 
Research in Europe, defines the Ultra green air transport system as a major high-level target for research in future solutions (Acare 2004). This emphasises the need of reducing the environmental impact of aircrafts and associated systems during their lifecycle: from manufacturing to operation, maintenance and disposal phase (Witik et al., 2012). Large Original Equipment Manufacturers (in their role of systems integrators), suppliers and sub-contractors are engaged in the development of lighter and more efficient solutions to reach these ambitious goals. The importance of this progress is undeniable; however, they might not be sufficient to label these solutions as 'sustainable'. Sustainability is not only related to the preservation of the natural environment and resources but also implies the ability to mitigate negative impacts on the social system (Broman and Robért 2017).

The research question underlying of this work focuses on how to raise decision makers awareness of the value and cost implications of being (or not being) 'sustainability compliant' when designing aerospace sub-systems and components. Due to their ability of representing and exemplifying real situations, systems, and mechanisms, serious games have been identified early on as a strong candidate to educate and stimulate the value-sustainability discussion. As shown in previous research, serious games are also well suited to support professionals in dealing with complex decision situations (Riedel and Hauge, 2011). The objective of this paper is initially to analyse the requirements for a serious game acting as 'boundary object' (Star, 2010) for a cross-disciplinary design team, facilitating knowledge sharing among the different disciplines and professional roles contributing to early stage design decision making. Later, the paper describes an instantiation of a serious game - as emerged from the field data - aimed at informing how environmental and social sustainability dimensions might influence customer satisfaction, production costs, safety or product performances along the entire lifecycle of a newly generated design concept. Eventually, the paper describes the results of verification activities aiming at testing the ability of the game to support negotiation across disciplinary boundaries in design.

\section{Related work}

Serious games have been extensively explored as a learning and training tool for students and professionals in many subjects, including sustainability. the literature features several games intended to raise awareness and increase knowledge and skills for sustainable development. These cover a wide range of topics (e.g. resource and energy consumption, building and product design, planning and management and also material selection) and target groups (citizens, students, researchers and professionals), using different modalities (individual or team). Serious games, such as the Global Goals for Sustainable development (https://gamethegoals.com/), have proven to be efficient mechanisms to spread knowledge about sustainability-related issues. However, games are not only used for informative purposes but also to generate a deeper understanding of the reasons behind these issues. Serious games work well to exemplify the complexity of environmental issues, to highlight cause-and-effect relationships associated to resource scarcity (Van der Wal et al., 2016), and to clarify the role of different stakeholders in situations that resemble the ones encountered in real life (Dib and Adamo-Villani, 2013). Some games are developed for the general public, as described by Morganti et al. (2017), and want to motivate a more sustainable consumer behaviour. Others are especially designed to educate and train students (as well as professionals) with technical and/or economics backgrounds. The explicit objective of these games is to provide applicable knowledge and skills to face environmental issues in professional environments, tasks, and organization. For instance, the serious game proposed by Dib and Adamo-Villani (2013) has shown to increase content learning and procedural knowledge among undergraduate students when teaching building sustainability practices. Serious games can be adapted to different levels of knowledge and experience. One example is the game proposed by Van der Wal et al. (2016), which is able to adapt to different groups, from water management professionals to master students. Noticeably, when playing the game, a team is usually required to identify a commonly agreed solution strategy to a given problem. The game is seen as a great conversation catalyst in this respect, supporting the different professional roles in the company in converging towards a common decision, even when different points of views and concerns regarding sustainability issues exist.

Another way to enhance understanding of the needs and views of different actors is role-playing. Rath et al. (2013) propose to involve students in a tutorial on sustainable innovation for product 
design based on role-play, in which teams of students are project teams of a fictitious company. In the game, research associates represent the board of management, while the members of a research group engaged in sustainable products development have the role of consultants. Students go through a series of 'quality gates' during the course, whose purpose is to mimic real world situations.

Debriefing sessions and follow up discussions are important learning mechanisms when playing serious games. For instance, Hirose et al. (2004) propose a game focused on the management of industrial waste. After the game is played, students engage in a follow-up discussions to further understand the issues related to illegal dumping, its relationship with the game, and to increase the overall interest in the environmental problem presented. The importance of having a post-game debriefing session is also highlighted by Whalen et al. (2018), who propose a serious game about material criticality and circular economy in education. The board game is turn-based, and participants take the role of CEOs of a manufacturing company, facing challenges related to material scarcity, price volatility, and environmental concerns. Their study shows the ability of the game to raise awareness on the sustainability matter, and to facilitate the development of critical thinking and system thinking skills.

In summary, serious games are acknowledged to support the development of both hard and soft skills. Furthermore, the different case studies highlight how versatile serious games can be, and how they can be applied to various contexts to answer the needs of different users. It shall be considered that serious games are not always trivial to play. Rather, many times they feature a medium-high degree of complexity due to the presence of simultaneous actors, objectives, and topics, which are necessary to make the game realistic and effective. Follow-up activities are seen an a way to increase game comprehension, as well as participants' interest and knowledge. The mentioned works use serious games for technical education and refer to the industrial sector. However, they are focused on a single problem (e.g. industrial waste management) or are not context specific (e.g. players represent a generic company). As explained in Section 1, the complexity and interrelation of sustainability issues need a holistic approach, and an effective serious game should be based on the knowledge of the specific sector (Riedel and Hauge, 2011). While a more general approach, teaching about single aspects, can be suitable for educational purposes, games for the industry need to picture a specific context in a complete way.

\section{Research method}

The Design Research Methodology (DRM) proposed by Blessing and Chakrabarti (2009) was used as the main reference throughout the research. DRM consists of four stages: Research Clarification (RC), Descriptive Study I (DS-I), Prescriptive Study (PS) and Descriptive Study II (DS-II). This paper covers a review-based RC, comprehensive DS-I and several cycles where the solutions was developed (PS) and verified with the practitioners (initial DS-II). The research was conducted in collaboration with a Swedish design-make supplier to major aero-engine Original Equipment Manufacturers. The case study selected for the development of the serious game is centred on the "responsibly sourced minerals" theme. This concerns the need to raise awareness among decision makers about the sustainability-related consequences of using so-called 'conflict materials' defined as natural resources extracted in a conflict zone and sold to perpetuate the fighting - for a given component or sub-system. The primary mode of data collection was semi-structured interviews: initially, a total of five respondents were sampled, covering a variety of roles, including design and cost engineers, risk management and material specialists, and sustainability experts. They were located using a snowballing technique: those initially fulfilling the theoretical criteria helped in locating others through their social network, to cover both the 'meatiest' cases and the 'peripheries'. After transcribing and validating the interviews, visual demonstrators of emerging modelling concepts were used to identify critical topics for the development of the serious games. The demonstrators include early prototypes of the game, which were initially tested by academics in several rounds, and later with progressively larger groups of practitioners at the partner company. Debriefing activities were conducted after each demonstration with the game participants, and the prototype was modified accordingly. 


\section{Descriptive study findings}

\subsection{Company requirements}

The field study pointed early on to the issue of critical materials in product design and development as a main candidate domain for the development of the serious game. Materials are defined as critical when they contain minerals that are extracted in armed conflict zones (conflict minerals) or conditions of exploitation or child labour, when their extraction exposes humans to potential health damages, causes environmental degradation and contamination, or when the material availability is scarce (Hallstedt and Isaksson, 2017). Importantly, the initial interviews confirm previous observations (e.g., Bertoni, 2017) showing that their use does not only imply an ethical question. Rather, critical materials can potentially disrupt the company business, and have profound implication on long-term profitability. On the one end, it is hard to predict their costs, because of their higher price sensitivity due to supply issues driven by conflicts. Furthermore, it is difficult to forecast the profitability of new technologies and products, because of shifting consumer behaviours e.g., due to their raised sustainability awareness, and changing legislations. The latter is well exemplified by the REACH (Registration, Evaluation, Authorisation and restriction of CHemicals) materials list (https://echa.europa.eu/substances-restricted-under-reach) in the E.U., that is continuously updated to reduce the impact of materials on human health and the environment. However, some critical materials allow to have lighter components weight, heat resistance and good functional performances. Therefore, balancing environmental, social and economic aspects to make the most overall sustainable choice is not a trivial task for companies. In fact, when comparing design or material alternatives, they should consider extremely complex and mutable factors and events i.e., global and local, economic and political balances. Moreover, intrinsic characteristics of the aerospace sector, as the presence of specific regulations and standards, long lead times, Time to Market, and aircraft lifespan make this target harder to achieve than in other sectors (EASA, 2019). Furthermore, as shown in previous studies (Hallstedt and Isaksson, 2017; Schöggl et al., 2017), interview respondents pointed to the lack of tools providing a holistic approach that considers sustainability in all its aspects, especially in the early stages that are crucial and, at the same time, extremely difficult to assess.

\subsection{General game requirements}

Stating the general requirements for a serious game is challenging. These are constrained by the specific context and there are few guidelines to follow. In the case study, the serious games assessment framework by Mitgutsch and Alvarado (2012), was used to define the general game requirements in the specific context being studied. The framework is composed of six elements, as shown in Figure 1.
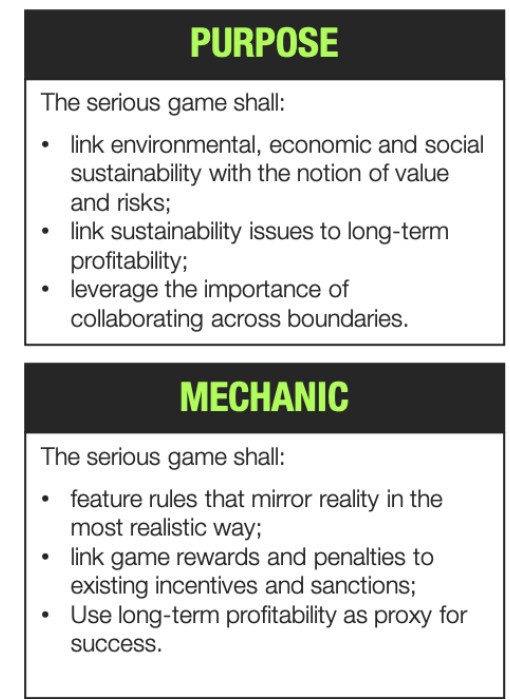

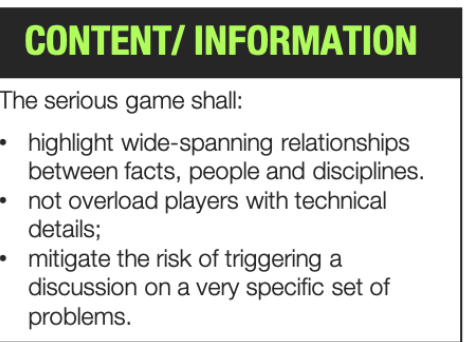

\section{FICTION/ NARRATIVE}

The serious game shall:

- shall represent a real context and situation;

- make players aware that they play in the company behalf;

- shorten physical and time distances, so that the players can experience the entire lifecycle for the product.

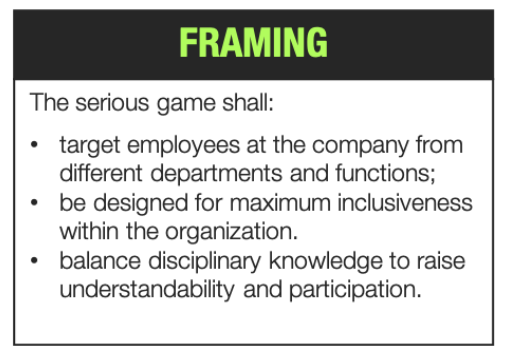

AESTETICS/ GRAPHICS

Figure 1. General game requirements gathered in the framework proposed by Mitgutsch and Alvarado (2012) 
In terms of overall Purpose, the game shall aim at creating a link between the three sustainability pillars (environmental, economic and social), with the notion of value and risks. It shall create an intuitive and visual understanding of how sustainability issues - related to various tasks, decisions, roles and external organizations - affect each other and, in turn long-term profitability. The game shall also leverage the importance of collaboration and knowledge sharing across organizational boundaries.

With regards to Content and Information, the game shall emphasise breadth rather that depth. It shall avoid digging into the technicalities of a solution, but rather highlight wide-spanning relationships between facts, people and disciplines. Indeed, the game shall not overload players with details, but rather keep the information display relatively simple and straightforward. This is seen to be beneficial to mitigate the risk of triggering a discussion on a very specific set of problems, losing sight of the overall game situation and general aim.

Looking at the Framing issue, the target group for the game is constrained to those individuals sharing the same overall company visions and working environment, i.e., employees at the company from different departments and functions. Yet, the game shall be designed for maximum inclusiveness within the organization. This means that players shall not necessarily share the same background and knowledge of product development, production, and management, nor of the way sustainability aspects need to be addressed. Rather, the game shall be able to balance disciplinary knowledge in a way that not only every phase is sufficiently understandable and clear for everyone, but to also stimulate players in taking decisions and actively contributing in achieving victory.

With regards to Mechanic, the rules of the game shall aim at mirroring reality in most realistic way, without hindering the aforementioned criteria of understandability and inclusions. For instance, a reward in the game shall correspond to an existing incentive, while a penalty shall represent a sanction which is likely to be enforced in the real world. Also, the in-game overall objective shall mimic that of a real-world company, which is the maximization of long-term profitability. The decisions taken by the players shall then be designed as effective metaphors of real world events.

In terms of Fiction and Narrative, the game shall represent a real context and situation. The players shall be aware that in the game they play in the company behalf, facing multiple problems related to product development, production, and trade. However, in the game, timespans and physical distances are shortened, so that the whole process is considered, getting together events and information that are fragmented in the world. This aspect is critical to make possible to the players to experience the entire lifecycle of the product during a single session of the game.

With regards to Aesthetic and graphic, the game shall feature recognizable symbols and an intuitive colours scheme, simplifying the comprehension of complex contents. The graphic should recall the context, in this case, industrial and aerospace, supporting players in relating the game to real-world situations and their working life in the company. Moreover, it should enhance the understanding of metaphors and events, expressing realism through pictures.

\section{Prescriptive study: Game development}

The proposed prototype resembles a classic board game that mixes the basic game mechanics from the Game of the Goose and Monopoly (https://monopoly.hasbro.com/it-it). Players follow the development, commercialization and end of life of a new aerospace product, moving across a board that represents the different steps of the product lifecycle. The game is both collaborative and competitive: each (multidisciplinary) team impersonates an aerospace company and competes against others teams in a closed market, as described in Section 4.2. The final goal is to make more money than the competition, taking the right decisions with regards to material selection, manufacturing process, market position and more. Reaching critical decision points (and the end of the board) before the other teams is rewarded with more freedom of choice. Throughout the game, each team must take sustainability-related choices that will have a minimal of significant impact on the long-term profitability of their in-game strategy. In the initial stages of the process, the game proceeds in a linear fashion, while during the commercialization phase of the product players conduct one or more loops depending on the longevity of the product. As in Monopoly, at the end of each loop players collect a reward. Players move across the board by rolling a dice to simulate randomness and to create a more dynamic game environment. 


\subsection{The phases}

The game stages were designed to mimic the life cycle of a product. Ideally, each of the phases is modelled upon the professional role of the participants in the company (i.e., management, design, procurement, production and cost, marketing). This is true except for the last phase, which is generic and asks for all participants to collaborate in the same way. In fact, identification with perspectives and goals in the game greatly supports learning and users' involvement (Bachen et al., 2016).

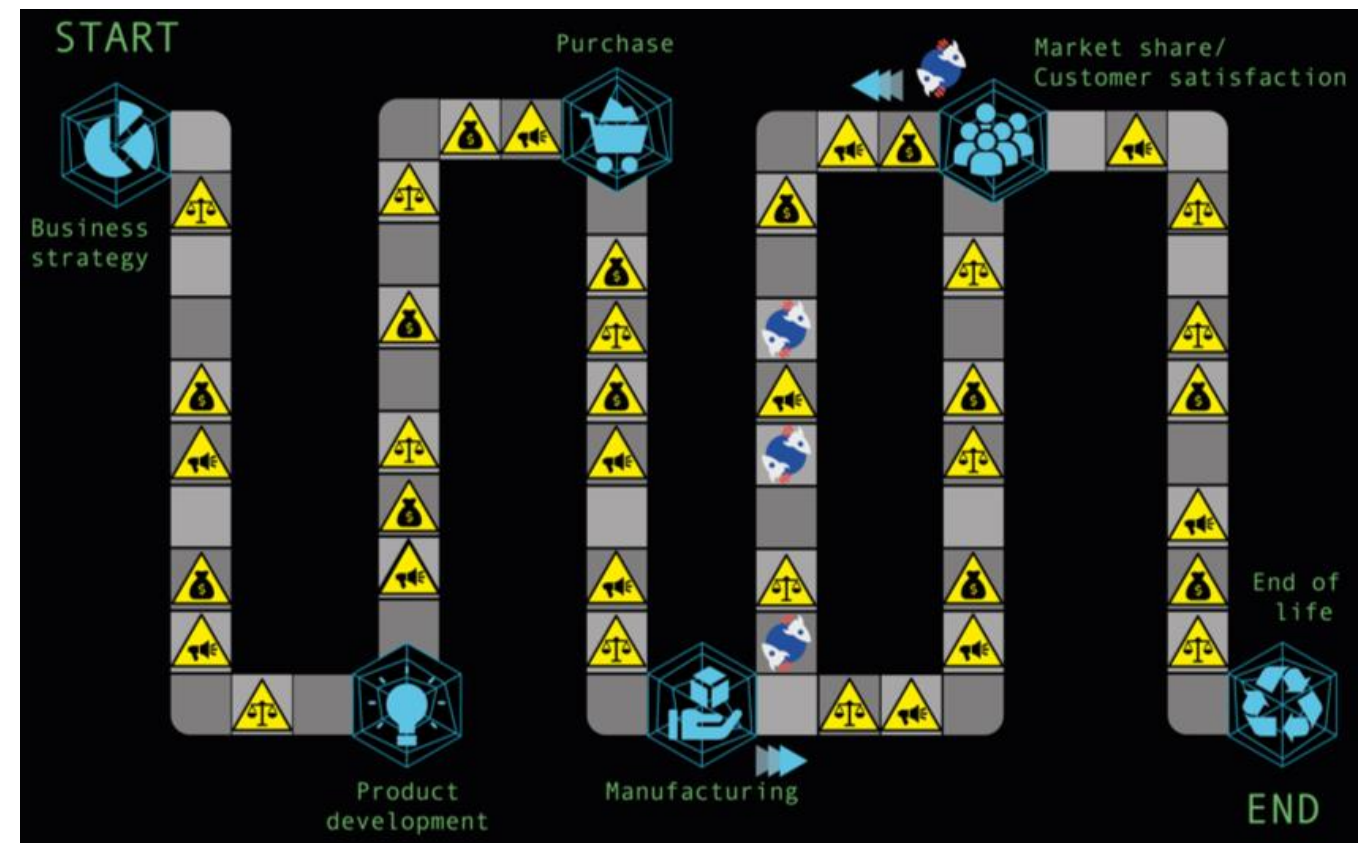

Figure 2. Prototype of the serious game board

There are six phases, in which participants have five options (cards) among which they can choose:

- Business strategy. Teams have to choose their target client profile (prioritizing low costs or prioritizing sustainability to different extents);

- Product development. Teams have to choose the kind of products they will develop (low cost to high performances);

- Purchase. The teams have to choose the material (low cost materials, low risks material or a balance);

- Manufacturing. Teams have to choose the supplier and/or the manufacturing site (selecting among a series of companies in different countries);

- Market share/customer satisfaction. Teams must decide how many years the product will be on the market (market share loops), this will determine their return on investment, but also add additional risks. One of them is to fall into a duel with a competitor, losing or gaining money;

- End of life. Teams have to choose among different end of life options (e.g. reuse, recycle, landfill).

The last two choices are affected by the previous ones: not all of them will be available). Decisions to be made are linked to the specific roles and phases, however, they are not detailed (e.g. material selection confront prices and sustainability features, not mentioning specific alloys). This is to respect the 'Content and information' and 'framing' requirements emerging from the descriptive study elements.

\subsection{Economic, social and environmental values}

As described in the game "purpose" element in Section 4.2, the aim of the game is to create a bond between economic, environmental and social sustainability values. In the game, these values are 
expressed by coins of three types, representing financial, environmental and social resources. More in detail, players during the game acquire, spend and manage so-called:

- 'money coins', representing the economic value and investments deriving from the team choices.

- 'environmental coins', representing the environmental cost of each choice (e.g. in terms of emissions and pollution).

- 'social coins', representing the social cost of each choice (e.g. in terms of risks of financing conflicts or child labour).

These budgets are set in the beginning and are different for each team depending on the kind of company they choose as target client. Whenever making a choice concerning product development and production the teams will have to invest their coins considering the three values, while in the market share phase they will gain back economic coins. If a team runs out of environmental and social coins, it will need to replenish its stock by using 'money coins' (at an exchange rate of 2 money coins for 1 environmental/social coin). The same exchange rate is applied at the end of the game when converting all coins into money to calculate the final score of each team. The use of coins is typical for many board games and is compliant with the requirement of using well-known visual elements stated in Section 4.2.

\subsection{Risks and opportunities}

The connection between the values described above should include an evaluation of related risks and opportunities. These are represented using two elements: Unexpected events and K-cards (or Knowledge Cards). The way these elements affect and are affected by events and decisions should reflect the one in reality, as required by the "mechanic" (Section 4.2).

When the players end up on one of the slots in the board containing the yellow triangle (see Figure 1) they have to pick an 'Unexpected Event' (e.g., the ones shown in Figure 3) card according to the symbol featured in the triangle. The game contains three types of cards:

- Social-political events (e.g. a conflict, a boycott campaign, a scandal);

- Economic events (e.g. currency value, E.U. funding, material demand);

- Legislative events (e.g. process or material bans, taxes, and incentives);
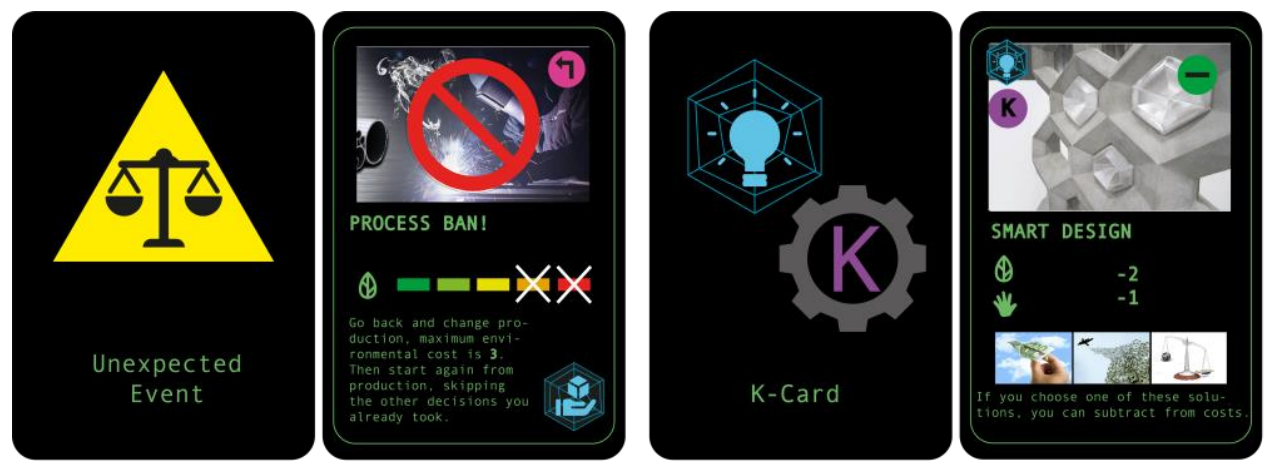

Figure 3. On the left: prototype of an example of legislative Unexpected Event cards; on the right: an example of K-card related to the decision phase 'Product Development'

The events affect the players based on their previous decisions in the game: they can have a negative outcome, giving penalties to be paid with coins (e.g. they select a critical material and then a conflict causes prices to rise), or assigning rewards (e.g. the E.U. is funding sustainable companies). In this case, they will gain coins or K-cards. The events cards contain images of actual events and phenomena, to respond the "aesthetic and graphic" requirement (Section 4.2) of recalling realistic situations. K-cards represent investments in $R \& D$ and can be bought or earned as a reward, they report a number between 0 and 2 that will allow the team to buy the correspondent number of solutions. Solutions cards can be played when making decisions in any phase, providing the possibility to reduce costs (e.g. making the design solution more performing or production more efficient). However, K-cards are not necessarily delivering a solution that is useful to the team, since the outcome of a research activity is not certain. 


\title{
6. Discussion: Results from the game testing sessions
}

The game was tested with practitioners from different departments of an aerospace company (material procurement, production and costs, R\&T) in two separate sessions. The first one featured five players divided into two teams and lasted for one and a half hours,. The second one involved six players divided in 3 teams and lasted approximatively one hour and 45 minutes. Both sessions were followed by a wrap-up discussion that focused on lessons learned, benefits, and areas of improvement for the game. The authors acted as moderators both in the game (explaining the rules and dispatching the cards/coins) and in the discussion. The latter aimed both at gathering a first evaluation of the gaming experience, and at assessing the ability of the game to represent the value creation opportunity and risks related to sustainability-compliant decisions. Also, the participants were asked to comment on the degree of complexity of the game. If too low, the game would hardly be exhaustive and comprehensive enough, while too much complexity would compromise the whole game experience and effectiveness. Other desirable feedback includes suggestions to individuate possible uses of the tool in the company and directions for improvements and future development.

\subsection{Involvement and learning}

Participants appreciated the overall game concept, finding it entertaining, representative and effective to picture the whole system, actors and events, as well as the complete process. One of the players commented:

\begin{abstract}
"Sometimes you do not experience this cycle in even one career, this is good to accelerate your experience. It is valuable to get the entire life-cycle. Especially for us who are very early in the $R \& T$ process. We do not think about the life-cycle so much, and this makes us think about it more."
\end{abstract}

They asserted that the idea of the social and environmental coins, transferable into money, was able to highlight the value of sustainability and to quantify it:

"The system with the coins is very interesting to communicate. The idea of having

"transfer" coins has potential. We speak often the language of dollars, still, it is good to see the trade factor between the value of sustainability."

Moreover, the chance of picking the 'unexpected event' cards (e.g. a card which ban a given production process) during the earliest stages of the game was rated as a positive way. Even if such a card did not have any effect on the gameplay in such an early stage, it made participants to better understand the dynamics of the game, while raising awareness on the potential long-term consequences of their design choices. In terms of game 'complexity', several participants acknowledged that it was not always easy to understand the meaning and impact of the different cards. They wished to have the opportunity to play the game more times, so to experience all the events and their associated consequences. Noticeably, complexity in this case has a positive connotation, which is it makes possible to play the game multiple times while continuing learning and keeping the participants engaged. Participants highlighted the need for a debriefing session following the game and the importance of having support during the game:

"The key thing is to have a moderator to lead the game. You need to lead the game a lot, you need to become familiar to be able to use it during training sessions for many people. There are many rules in fact."

This feedback was expected since it is common for serious games, as discussed in Section 2. The testing activity further pointed out that potential uses of the game include training sessions, for instance during periodical meeting in the departments:

"It is an idea that of playing it at the department, at the departmental day and spend half a day on it and have some reflections on sustainability, i.e., to understand consequences and things." 
The game was also defined as a communication tool to discuss and convey ideas and reflections to the management department. A participant compared the game to a kind of system or algorithm to calculate sustainability value, suggesting the idea of creating a simulation model that is based on the game. It was also suggested to play it with more than two teams, so the risk of picking bad choices would be higher:
"It would be interesting to have more teams so that some teams are forced to play with what you get. Sometimes we do not pick even the strategy. This would be interesting to try, get a strategy and make the best out of it. Many times we want to be green and we have a strategy that is constraining us."

Regarding this aspect, the game would need an adjustment to guarantee that a session would last no more than two hours: otherwise, it would be hard to keep people interested. This could be done by reducing the recurrence of unexpected events. Other possible improvements of the game include clarifying when the K-cards can be bought and played, as well as content of the cards and board, that were sometimes challenging to understand for participants.

\section{Discussion and conclusions}

The need to address multiple and sometimes contrasting sustainability goals is one of the main challenges that companies face in the global market. The case of the aerospace industry is particularly critical, because of the high environmental impact of air transport, which is raising the public attention, and the extremely complex operational processes and regulations typical of this sector. The serious game proposed in this paper addresses this issue and wants to raise awareness of the value, risk and impact of sustainability-related choices in concept design.

Several development directions for the serious game have been identified based on the feedback received from the company practitioners. Firstly, the complexity of the game will be reduced without compromising its richness and detail, which was found to be instrumental for the success of the testing activity. Future work will be focused on streamlining the layout and the design of cards, board and icons, to make their meaning and effect clearer. The reward/penalty system will also be re-calibrated to create a more realistic experience. The role of the moderator will be further investigated, developing instructions and manuals to support the 'game master' in the task of handling pre-game, in-game and post-game activities. The authors are also considering developing an online version for the game, where engineers can 'train' and get acquainted with its logic and rules.

From a design research perspective, future work will deepen the results of the descriptive study and will focus on the development of additional demonstrators (prototypes) for the serious game Testing activities will be scaled up and involve a larger number of players, gathering more qualitative data from game activity. An opportunity is seen with regards to recording the gaming session and analysing it using protocol analysis, by means of an appropriate coding scheme. This is expected to reveal those specific game features that contribute the most in raising awareness of the relationship between value, sustainability and risk for new products. Future activities will also aim at assessing the efficacy of the game when it comes to trigger new reflections and strategies for sustainable development in the company. The game seems now to support a weak, rather than strong, sustainability approach (Neumayer, 1999), mainly because it moves from the assumption that economic and natural capital are tradeable parameters. A strong sustainability approach is proposed in the model by Gaziulusoy et al. (2013). In this case, practitioners participate in two separate and distant sessions, allowing time for reflections: having more sessions, letting the former affecting the latter, may be a way to discuss further and deeper sustainability related choices, their consequences and future scenarios.

\section{References}

ACARE (2004), Strategic Research Agenda 2- Executive summary. Advisory Council for Aeronautics Research in Europe.

Bachen, C.M. et al. (2016), "How do presence, flow, and character identification affect players' empathy and interest in learning from a serious computer game?", Computers in Human Behavior, Vol. 64, pp. 77-87. https://doi.org/10.1016/j.chb.2016.06.043 
Bertoni, M., Hallstedt, S. and Isaksson, O. (2015), "A Model-Based approach for sustainability and value assessment in the aerospace value chain", Advances In Mechanical Engineering, Vol. 7 No. 6, pp. 1-19.

Bertoni, M. (2017), "Introducing sustainability in value models to support design decision making: A systematic review", Sustainability, Vol. 9 No. 6, p. 994. https://doi.org/10.3390/su9060994

Blessing, L.T.M. and Chakrabarti, A. (2009), DRM, a Design Research Methodology, Springer, London. https://doi.org/10.1007/978-1-84882-587-1

Broman, G.I. and Robèrt, K.H. (2017), "A framework for strategic sustainable development”, Journal of Cleaner Production, Vol. 140, pp. 17-31.

Dib, H. and Adamo-Villani, N. (2013), "Serious sustainability challenge game to promote teaching and learning of building sustainability", Journal of Computing in Civil Engineering, Vol. 28 No. 5, p. A4014007. https://doi.org/10.1061/(ASCE)CP.1943-5487.0000357

EASA (2019), European aviation environmental report [online]. European Aviation Safety Agency. Available at: https://ec.europa.eu/transport/sites/transport/files/2019-aviation-environmental-report.pdf (accessed 0511.2019).

Hallstedt, S. and Isaksson, O. (2017), "Material criticality assessment in early phases of sustainable product development", Journal of Cleaner Production, Vol. 161, pp. 40-52. https://doi.org/10.1016/j.jclepro. 2017.05.085

Hirose, Y., Sugiura, J. and Shimomoto, K. (2004), "Industrial waste management simulation game and its educational effect", Journal of Material Cycles and Waste Management, Vol. 6 No. 1, pp. 58-63. https://doi.org/10.1007/s10163-003-0108-4

Gaziulusoy, A.I., Boyle, C. and McDowall, R. (2013), "System innovation for sustainability: a systemic doubleflow scenario method for companies", Journal of Cleaner Production, Vol. 45, pp. 104-116. https://doi.org/10.1016/j.jclepro.2012.05.013

Kousoulidou, M. and Lonza, L. (2016), "Biofuels in aviation: Fuel demand and CO2 emissions evolution in Europe toward 2030", Transportation Research Part D: Transport and Environment, Vol. 46, pp. 166-181. https://doi.org/10.1016/j.trd.2016.03.018

Leigh Star, S. (2010), "This is not a boundary object: Reflections on the origin of a concept", Science, Technology, \& Human Values, Vol. 35 No. 5, pp. 601-617.

Lubin, D.A. and Esty, D.C. (2010), "The sustainability imperative”, Harvard business review, Vol. 88 No. 5 , pp. $42-50$.

Mitgutsch, K. and Alvarado, N. (2012), "Purposeful by design: a serious game design assessment framework", Proceedings of the International Conference on the foundations of digital games, ACM, pp. 121-128. https://doi.org/10.1145/2282338.2282364

Morganti, L. et al. (2017), "Gaming for Earth: Serious games and gamification to engage consumers in proenvironmental behaviours for energy efficiency”, Energy Research \& Social Science, Vol. 29, pp. 95-102, https://doi.org/10.1016/j.erss.2017.05.001

Neumayer, E. (1999). Weak versus strong sustainability. Books.

Rath, K. et al. (2013), "Tutorial sustainable innovations - An innovative role-play concept for education", Proceedings of the 19th International Conference on Engineering Design (ICED13), Design for Harmonies, Vol. 8: Design Education, Seoul, Korea, 19-22.08. 2013.

Riedel, J.C.K.H. and Hauge J.B. (2011), "State of the art of serious games for business and industry", 17th International Conference on Concurrent Enterprising, IEEE, pp. 1-8.

Schöggl, J.P., Baumgartner, R.J. and Hofer, D. (2017), "Improving sustainability performance in early phases of product design: A checklist for sustainable product development tested in the automotive industry", Journal of Cleaner Production, Vol. 140, pp. 1602-1617. https://doi.org/10.1016/j.jclepro.2016.09.195

Van der Wal, M.M. et al. (2016), "Can computer models be used for social learning? A serious game in water management", Environmental modelling \& software, Vol. 75, pp. 119-132, https://doi.org/10.1016/j. envsoft.2015.10.008

Watze, M. and Hallstedt, S.I. (2019), "Profile model for management of sustainability integration in engineering design requirements", Journal of Cleaner Production, p. 119155. https://doi.org/10.1016/j.jclepro.2019.119155

Whalen, K.A. et al. (2018), “'All they do is win': Lessons learned from use of a serious game for Circular Economy education", Resources, Conservation and Recycling, Vol. 135, pp. 335-345. issn: 0921-3449. http://dx.doi.org/10.1016/j.resconrec.2017.06.021

Willard, B. (2012), The new sustainability advantage: seven business case benefits of a triple bottom line, New Society Publishers.

Witik, R.A. et al. (2012), "Economic and environmental assessment of alternative production methods for composite aircraft components", Journal of Cleaner Production, Vol. 29, pp. 91-102. 